\title{
Evaluation and Analysis: Development Trend of China's Logistics Industry under Supply Chain Globalization Environments
}

\author{
Juping Shao ${ }^{1,2}$, Tianyun $\mathrm{Ma}^{3}$, Shaohua Dong ${ }^{2}$, Xianghua Meng ${ }^{1}$ \\ ${ }^{1}$ School of Management, Ludong University, Yantai, Shandong Province, China; ${ }^{2}$ Department of Logistics Engineering, University \\ of Science and Technology, Beijing, China; ${ }^{3}$ School of Civil Engineering, Ludong University, Yantai, Shandong Province, China. \\ Email: wlustbshao@163.com,ytmty2477@126.com,dsh_dle@me.ustb.edu.cn,daitoue0279@vip.sina.com
}

Received February $20^{\text {th }}, 2009$; revised April 21 ${ }^{\text {st }}, 2009$; accepted May $25^{\text {th }}, 2009$.

\begin{abstract}
First in this paper a systematic and comprehensive hybrid index evaluation system of regional logistics competitiveness is designed according to the characteristics of China's regional logistics system under supply chain globalization environments, and systematic analysis and discussion of the connotation of the various factors in the index evaluation system are made. Then based on hierarchy analysis thought and fuzzy decision-making principles, the development trend of China's regional logistics industry is assessed systematically and comprehensively. With the result of the above assessment, the key factors and the gradual evolution process of promoting regional logistics industry competitiveness under supply chain globalization environments are discussed. Also, in this paper it points out that enhancing the strength of urban logistic enterprises will promote the competitiveness of regional logistics industry. And the logistics competitiveness of a few major economic zones in China is discussed with conclusion that discrepancy exists in terms of China's provincial capital city's logistics development. At last, development strategies for regional logistics are put forward aimed at the west regions of China which have weak competitiveness in logistics industry.
\end{abstract}

Keywords: supply chain globalization environment, regional logistics, developmental trend, evaluation and analysis

\section{Introduction}

From the late 1990s, a new round of international industrial transfer, which is characterized by the transfer of manufacturing industry from developed countries to China as well as other eastern Asian countries, has been on the increase with the rise of knowledge economy and the acceleration of global economy. This has accelerated the globalization of supply chains, and hence has made regional logistics more demanding [1]. The level of logistics industry development has become an important indicator, which is used to measure the quality of the regional investment environment, but also becomes an accelerator to the regional economy. To enhance the capability of regional logistics system under supply chain globalization environments and to improve the investment environment so that to attract more investment capital, each region should accelerate the construction of infrastructure investment, based on the scientific and rational planning of the regional logistics development, and integrate and optimize the traditional logistics industry and improve the concentration of regional logistics industry, which plays an important role in enhancing the regional comprehensive competitiveness and the sustainable development of regional economy under supply chain globalization environments.

Based on the statistical data of China's four municipalities and 27 provincial capital cities related to the logistics industry in 2007 and a tentative construction of the assessment index system for regional logistics development, applying the thought of hierarchy analysis [2] , fuzzy pattern recognition principles and fuzzy consistent judgment matrix $[3,4,5,6]$, the article offers the hybrid index hierarchy fuzzy decision-making method to synthetically analyze and evaluate the development trend of Chinese regional logistics.

\section{The Construction of Evaluation Index and the Data Standardization Processing}

\subsection{The Construction of Evaluation Index}

The competitiveness of area logistics is the joint force from the interplay of various factors. According to the 
characteristics of regional logistics and following some principles about evaluation index, the paper summarizes the evaluation index system into 12 index of first class $M_{i}$ (for $\mathrm{i}=1,2, \ldots, 12$ ), including such elements as economic situation, the logistics volume, the logistics industry practitioners, the logistics facilities and equipments, the logistics industry costs, postal communications status, foreign investment, the standard of education, science and technology, trade status, information status, geographical situation and industrial policy environment. Those first class index elements include 22 second class index which is indicated by $S_{i j}^{k}$ (represent the $\mathbf{j}^{\text {th }}$ second-degree index about the $\mathbf{i}^{\text {th }}$ first class index in the $\mathbf{k}^{\text {th }}$ evaluated region), and all these elements compose a threetier system of mixed indicators, as shown in Figure 1.

(1) Economic situation $M_{1}$ : including the monthly average wage of all workers and the employment staff in per 10,000 people. These indicators comprehensively reflect the socio-economic basis of the regional logistics development.

(2) The logistics volume $M_{2}$ : mainly includes the goods turnover per capita. The indicator reflects the demand of the situation and the scale in the regional logistics services.

(3) The logistics industry practitioners $M_{3}$ : mainly includes Logistics industry practitioners in per 10,000 employment staff. The indicator reflects the needing situation of the human resources in the regional logistics industry development.

(4) The logistics facilities and equipments $M_{4}$ : mainly includes per capita area of the road, per 10,000 people the number of having transport vehicles, per capita investment of the logistics industry, per 10,000 people the number of having public transport vehicles. These indicators reflect the infrastructure conditions of a regional logistics industry development from different angles.
(5) The logistics industry costs $M_{5}$ : mainly includes per 10,000 people the output of logistics industry, per 10,000 people the increase amount in the inventory, and the two indicators reflect the effectiveness of the regional logistics industry from different perspectives.

(6) Postal communications status $M_{6}$ : mainly includes per 10,000 people the number of owning Mobile Phone, per 10,000 people the number of having Internet, per 10,000 people the number of having sub-post office. These indicators reflect the information infrastructure status of the regional logistics development from different perspectives.

(7) Attract foreign investment status $M_{7}$ : mainly includes per 10,000 people the amount of having foreign capital investment, the indicator reflects the vitality and attractive situations of the regional logistics industry development.

(8) The standard of education, science and technology $M_{8}$ : mainly includes per 10,000 people the number of having college students in school, per capita the amount of education expenditure spending, logistics and information industry technology professionals in per 10,000 employment staff, these indicators reflect trained personnel resources status of the regional logistics industry development from different perspectives.

(9) Trade status $M_{9}$ : mainly includes per capita the wholesale/retail trade amount of year-end inventory, per capita total import/export amount of goods, the two indicators reflect the needs conditions and needs scale of the regional logistics service from trade perspectives.

(10) Information Condition $M_{10}$ : indicates by information index, the information index is an important indicator, which reflects the competitiveness of a region in the information age. It is comprehensively calculated by 20 indicators of six aspects, which includes the development and utilization of resources, information network construction, the application of information technology,

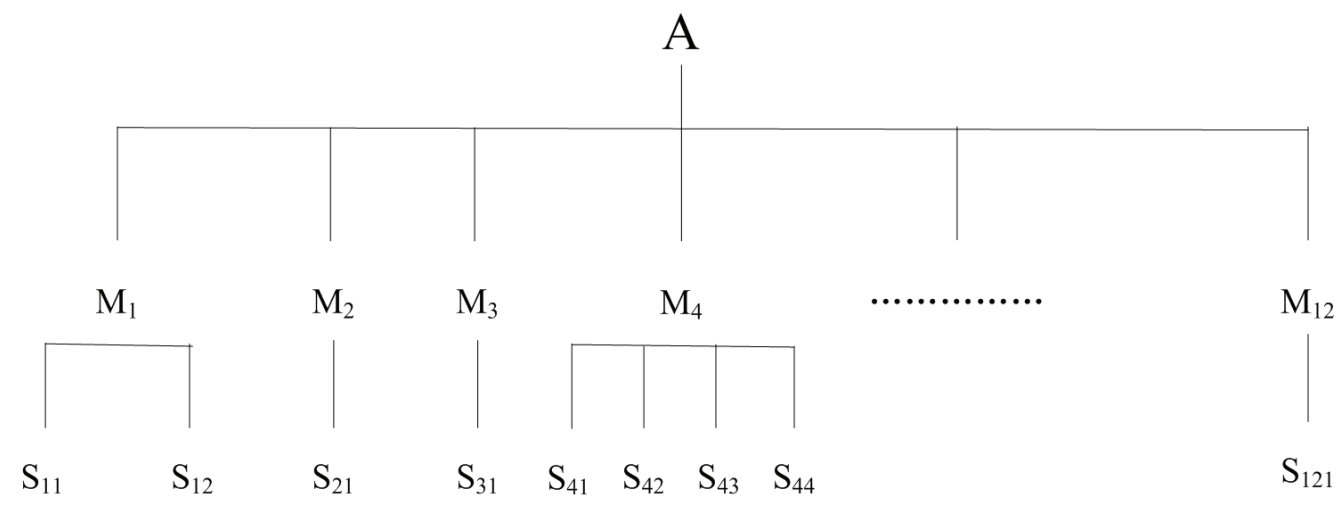

Figure 1. Regional logistics system evaluation index system 
information products and services, information human resources and the development environment of information.

(11) Geographical condition $M_{11}$ : geographic location is obviously one of the important factors influencing the development of the logistics industry.

(12) Industrial policy environment $M_{12}$ : the local industry system, industrial policies and market economy atmosphere and the idea and consciousness of the local people have a wide impact on the development of logistics industry, so industrial policy environment also affects the development of the logistics industry as one of the important factors.

\subsection{Determine Evaluation Index Set}

According to AHP, Figure 1 shows the evaluation index system, which consists of the target layer $A$, middle layer (first class index) $M_{i}$, and the bottom layer (second-degree index) $S_{i j}^{k}$ (represent the $\mathbf{j}^{\text {th }}$ second-degree index about the $\mathbf{i}^{\text {th }}$ first class index in the $\mathbf{k}^{\text {th }}$ evaluated region). $A$ is the set of first class index $M_{i}$, of which the notation is $A=\left\{M_{1}, M_{2}, \ldots \ldots, M_{m}\right\} . M_{i}$ (for $\mathrm{i}=1,2, \ldots, \mathrm{m}$ ) is the set of second-degree index $S_{i j}^{k}$ (for $j=1,2, \ldots, n_{i}$, and $n_{i}$ is the number of second-degree index in the $i^{\text {th }}$ first class index), and use the set $M_{i}=\left\{S_{i 1}^{k}, S_{i 2}^{k}, \ldots \ldots ., S_{i n_{i}}^{k}\right\}$ to represent. Then

$$
\begin{array}{ll}
A=\bigcup_{i=1}^{m} M_{i} & M_{i} \cap M_{j}=\phi, i \neq j \\
S_{i j_{x}}^{k} \cap S_{i j_{y}}^{k}=\phi, j_{x} \neq j_{y} & \\
j_{x}=1,2, \ldots ., n_{i} & j_{y}=1,2, \ldots ., n_{i}
\end{array}
$$

\subsection{Handle the Mixed Indicator $S_{i j}^{k}$}

Let's suppose that the number of evaluated region is $n$ and the number of first class index is $m$. For an evaluated region $k, f_{i j}^{k}(x) \quad(k=1,2, \cdots, n)$ is the $\mathrm{j}^{\text {th }}$ value of the second-degree index $S_{i j}^{k}$ in the $i^{\text {th }}$ first class index $M_{i}$. Now define the target characteristic matrix of the $\mathrm{i}^{\text {th }}$ first class index by $X_{i}=\left(f_{i j}^{k}(x)\right)_{n_{i} \times n}$.

We compute quantitative indexes by basic date. As for the qualitative index in the article, the set of fuzzy language is defined as $\mathrm{L}=\{\mathrm{EG}, \mathrm{VG}, \mathrm{G}, \mathrm{F}, \mathrm{P}\}$, in which, $\mathrm{EG}=$ extremely good, $\mathrm{VG}=$ very good, $\mathrm{G}=$ good, $\mathrm{F}=$ fair, $\mathrm{P}=$ poor. The definite value is determined by experts giving a mark according to actual circumstance. Fuzzy value is indicated with $(0,1)$. In the article, the "geo- graphic situation" and the "industrial policy environment" are two qualitative indicators in first class index, and the definition of evaluation indicators for the assessment as VG value of 0.95 , evaluation indicators assessed as $G$ value 0.85 , evaluation indicators assessed value of 0.75 for $F$ and evaluation indicators for the assessment of $\mathrm{P}$ value was 0.65 , for the VP to inform the evaluation index value of 0.55 . The final value of each qualitative index is the average points of all the experts' points.

\subsection{The Data Standardization Processing}

To eliminate the effect of different indexes unit, and to integrate quantitative indexes and qualitative indexes, we need to process all indexes data so that they are standardization data.

For each index $S_{i j}^{k}, \varphi_{i j}^{k}(x)$ is the standardization value of the $\mathbf{j}^{\text {th }}$ second-degree index about the $\mathbf{i}^{\text {th }}$ first class index in the $\mathbf{k}^{\text {th }}$ evaluated region. When the index original data is $f_{i j}^{k}(x)$, the definition of standardization value $\varphi_{i j}^{k}(x)$ is determined by the following equation

$$
\begin{aligned}
\varphi_{i j}^{k}(x) & =\frac{f_{i j}^{k}(x)-\overline{f_{i j}^{k}(x)}}{s} \\
i & =1,2, \ldots ., m \\
j & =1,2, \ldots ., n_{i} \\
k & =1,2, \cdots, n
\end{aligned}
$$

In the equation,

$$
\begin{gathered}
s=\sqrt{\frac{\sum_{k=1}^{n}\left(f_{i j}^{k}(x)-\overline{f_{i j}^{k}(x)}\right)^{2}}{n}} \\
\overline{f_{i j}^{k}(x)}=\frac{\sum_{k=1}^{n} f_{i j}^{k}(x)}{n}
\end{gathered}
$$

From Formula (3), the standardization evaluation matrix of all indexes is obtained. This is written as follows: $R_{i}=\left(\varphi_{i j}^{k}(x)\right)_{n_{i} \times n}$.

Applying Formulae (3), (4) and (5), the original data of China's four municipalities and 27 province capital cities can be processed and standardized. The processing results are shown in Table 1.

\section{Fuzzy Subset of Index Weight}

To avoid the problem of poor uniformity of judgment matrix in the process of computing weight in AHP, we use fuzzy consistent judgment matrix $G$ which exist in fuzzy consistent relations to obtain weight. Suppose that 
Table 1. The results of data standardization processing

\begin{tabular}{lccccccccc}
\hline Region & $\varphi_{11}$ & $\varphi_{12}$ & $\varphi_{21}$ & $\varphi_{31}$ & $\varphi_{41}$ & $\varphi_{42}$ & $\varphi_{43}$ & $\varphi_{44}$ & $\varphi_{i j}$ \\
\hline Peking & 2.29 & 0.70 & -0.63 & -0.21 & 0.36 & 0.09 & -0.34 & 3.25 \\
Tianjin & 0.91 & -0.82 & 2.70 & -0.19 & -0.03 & -0.38 & -0.59 & 0.09 & $\ldots$ \\
Shanghai & 2.70 & -0.06 & 3.79 & 0.01 & 1.76 & 0.86 & 0.37 & 1.47 & $\ldots$ \\
Nanjing & 0.30 & 1.29 & 0.09 & -0.40 & 2.28 & 0.98 & 2.97 & -0.31 & $\ldots$ \\
Hangzhou & 1.47 & 0.20 & 0.24 & -0.29 & 1.91 & 3.42 & 1.62 & 0.19 & $\ldots$ \\
Hefei & -0.76 & 0.00 & -0.15 & -0.31 & 0.45 & -0.99 & -0.29 & -0.49 & $\ldots$ \\
Fuzhou & 0.01 & -0.05 & -0.21 & -0.36 & 0.25 & -0.82 & -0.07 & 0.10 & $\ldots$ \\
Nanchang & -0.77 & -0.44 & -0.46 & -0.22 & -0.35 & -1.19 & 0.25 & -0.39 & $\ldots$ \\
Jinan & -0.35 & 2.15 & 1.27 & -0.36 & 0.82 & -0.27 & 0.05 & -0.73 & $\ldots$ \\
Zhengzhou & -0.72 & 1.76 & 0.16 & -0.31 & -0.37 & -1.17 & 1.51 & -0.43 & $\ldots$ \\
Wuhan & -0.74 & 0.75 & -0.21 & -0.18 & -0.06 & -0.88 & 0.56 & -0.39 & $\ldots$ \\
Changsha & -0.42 & 0.24 & -0.14 & 0.58 & -0.47 & -0.98 & 0.33 & -0.25 \\
Guangzhou & 1.19 & 2.16 & 0.85 & -0.24 & 0.20 & 0.34 & 2.51 & -0.70 & $\ldots$ \\
Chongqing & -0.38 & -0.73 & -0.68 & -0.12 & -1.47 & 0.64 & -0.66 & -0.50 \\
\hline k & $\ldots$ & $\ldots$ & $\ldots$ & $\ldots$ & $\ldots$ & $\ldots$ & $\ldots$ & $\ldots$ \\
\hline
\end{tabular}

Note: The source of statistical original data is rooted in the reference literature [7], [8] and [9] which were computed simply. Because there were a large number of statistical indexes and original data, but the paper length is limited, so only part of the results of data standardization processing was shown in table1 in the article.

$\omega_{i}$ (for $\left.i=1, \ldots, m\right)$ is first class indexes weight, and $\omega_{i j} \quad\left(\right.$ for $i=1, . ., m$, and $\left.j=1,2, \ldots ., n_{i}\right)$ is second-degree index weight; We have

$$
\sum_{i=1}^{m} \omega_{i}=1 \quad \sum_{j=1}^{n_{i}} \omega_{i j}=1
$$

Computing the index weight process is as follows:

Step 1 Establish optimal choice relationship matrix $F=\left(\sigma_{p q}\right)_{n_{i} \times n_{i}}$
The value of $\sigma_{p q}$ in this matrix separately is 0.5 (the importance of the two indexes is on the same level), 0.0 (one index is less importance than another), 1.0 (one index is more importance than another). The relative importance degree of the index is given by the experts beforehand.

According to the relevant data and the experts' judgment, establish the optimal choice relationship matrix $F$ of the first class indexes are shown as follows:

$$
F=\left(\begin{array}{cccccccccccc}
0.5 & 1 & 1 & 1 & 1 & 1 & 1 & 1 & 1 & 1 & 1 & 1 \\
0 & 0.5 & 1 & 0 & 1 & 1 & 1 & 0 & 0 & 0 & 0 & 0 \\
0 & 0 & 0.5 & 0 & 0 & 1 & 1 & 0 & 0 & 0 & 0 & 0 \\
0 & 1 & 1 & 0.5 & 1 & 1 & 1 & 1 & 1 & 1 & 1 & 1 \\
0 & 0 & 1 & 0 & 0.5 & 1 & 1 & 0 & 0 & 0 & 0 & 0 \\
0 & 0 & 0 & 0 & 0 & 0.5 & 1 & 0 & 0 & 0 & 0 & 0 \\
0 & 0 & 0 & 0 & 0 & 0 & 0.5 & 0 & 0 & 0 & 0 & 0 \\
0 & 1 & 1 & 0 & 1 & 1 & 1 & 0.5 & 1 & 1 & 1 & 1 \\
0 & 1 & 1 & 0 & 1 & 1 & 1 & 0 & 0.5 & 1 & 1 & 1 \\
0 & 1 & 1 & 0 & 1 & 1 & 1 & 0 & 0 & 0.5 & 0 & 0 \\
0 & 1 & 1 & 0 & 1 & 1 & 1 & 0 & 0 & 1 & 0.5 & 1 \\
0 & 1 & 1 & 0 & 1 & 1 & 1 & 0 & 0 & 1 & 0 & 0.5
\end{array}\right)
$$

In addition, according to the actual situation of evaluation indexes design, the second class indexes which are related with a first class index are of same importance, that is, the value of $\sigma_{p q}$ in optimal choice relationship matrix $F=\left(\sigma_{p q}\right)_{n_{i} \times n_{i}}$ is 0.5 . Thus the optimal choice relationship matrix of the second class index is omitted.

Step 2 Establish fuzzy consistent judgment matrix $G=\left(r_{p q}\right)_{n_{i} \times n_{i}}$ 


$$
\begin{aligned}
& r_{p}=\sum_{k=1}^{n_{i}} \sigma_{p k}, p=1,2, \cdots n_{i} \\
& r_{p q}=\frac{r_{p}-r_{q}}{2 n_{i}}+0.5
\end{aligned}
$$

From the literature [10] we know that $G$ meets fuzzy consistent relationship. Thus, according to Formula (7) and optimal choice relationship matrix $F$, we could establish fuzzy consistent relationship matrix $G$ of the first class index as follows:

$G=\left(\begin{array}{llllllllllll}0.5 & 0.792 & 0.875 & 0.542 & 0.833 & 0.917 & 0.958 & 0.583 & 0.625 & 0.75 & 0.667 & 0.708 \\ 0.792 & 0.5 & 0.583 & 0.25 & 0.542 & 0.625 & 0.667 & 0.292 & 0.333 & 0.458 & 0.375 & 0.417 \\ 0.875 & 0.583 & 0.5 & 0.167 & 0.458 & 0.547 & 0.583 & 0.208 & 0.25 & 0.375 & 0.292 & 0.333 \\ 0.542 & 0.25 & 0.167 & 0.5 & 0.792 & 0.875 & 0.917 & 0.542 & 0.583 & 0.708 & 0.625 & 0.667 \\ 0.833 & 0.542 & 0.458 & 0.792 & 0.5 & 0.583 & 0.625 & 0.25 & 0.292 & 0.417 & 0.333 & 0.375 \\ 0.917 & 0.625 & 0.547 & 0.875 & 0.583 & 0.5 & 0.542 & 0.167 & 0.208 & 0.333 & 0.25 & 0.292 \\ 0.958 & 0.667 & 0.583 & 0.917 & 0.625 & 0.542 & 0.5 & 0.125 & 0.167 & 0.292 & 0.208 & 0.25 \\ 0.583 & 0.292 & 0.208 & 0.542 & 0.25 & 0.167 & 0.125 & 0.5 & 0.542 & 0.667 & 0.583 & 0.625 \\ 0.625 & 0.333 & 0.25 & 0.583 & 0.292 & 0.208 & 0.167 & 0.542 & 0.5 & 0.625 & 0.542 & 0.583 \\ 0.75 & 0.458 & 0.375 & 0.708 & 0.417 & 0.333 & 0.292 & 0.667 & 0.625 & 0.5 & 0.417 & 0.458 \\ 0.667 & 0.375 & 0.292 & 0.625 & 0.333 & 0.25 & 0.208 & 0.583 & 0.542 & 0.417 & 0.5 & 0.542 \\ 0.708 & 0.417 & 0.333 & 0.667 & 0.375 & 0.292 & 0.25 & 0.625 & 0.583 & 0.458 & 0.542 & 0.5\end{array}\right)$

Step 3 Computes the largest eigenvalue of $G$, after Normalization of the corresponding vector, we can get $\omega_{i}$ and $\omega_{i j}$.

Applying the tool of MATLAB or SPSS, we can eas-

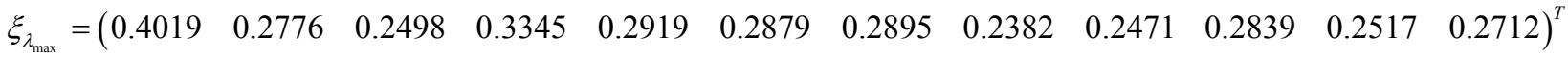

After eigenvector $\xi_{\lambda_{\max }}$ normalized, we get the weight about first class index as follows:

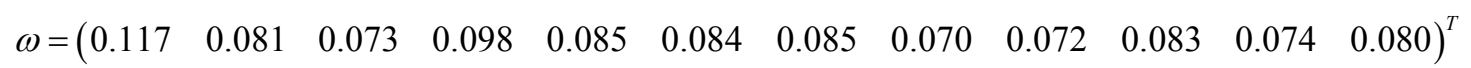

The weights about second-degree index are shown in the Table 2.

\section{Comprehensive Evaluation}

Suppose $u_{i}^{k}(x)$ is the first class index evaluation value ily obtain the greatest eigenvalue $\lambda_{\max }=0.6148$ about $G$, and the largest eigenvalue corresponding eigenvector as follows:

$$
u_{i}^{k}(x)=\sum_{j=1}^{n_{i}} \omega_{i j} \varphi_{i j}^{k}(x) \quad i=1,2, \ldots, m
$$

\begin{tabular}{|c|c|c|c|c|c|c|c|c|c|c|c|}
\hline$S_{i j}^{k}$ & $s_{11}$ & $S_{12}$ & $S_{21}$ & $S_{31}$ & $S_{41}$ & $S_{42}$ & $s_{43}$ & $s_{44}$ & $s_{51}$ & $s_{52}$ & $s_{61}$ \\
\hline$\omega_{i j}$ & 0.5 & 0.5 & 1 & 1 & 0.25 & 0.25 & 0.25 & 0.25 & 0.5 & 0.5 & 0.33 \\
\hline$S_{i j}^{k}$ & $s_{62}$ & $s_{63}$ & $S_{71}$ & $s_{81}$ & $s_{82}$ & $S_{83}$ & $s_{91}$ & $s_{92}$ & $S_{101}$ & $s_{111}$ & $s_{121}$ \\
\hline$\omega_{i j}$ & 0.33 & 0.33 & 1 & 0.33 & 0.33 & 0.33 & 0.5 & 0.5 & 1 & 1 & 1 \\
\hline
\end{tabular}

Table 2. The weights about second-degree index 


$$
U_{A}^{k}\left(u_{i}^{k}(x)\right)=\sum_{i=1}^{m} \omega_{i} u_{i}^{k}(x)
$$

applying Formulae (8) and (9), we can get the overall objective vector $U=\left(U_{A}^{1}, U_{A}^{2}, \cdots U_{A}^{k} \cdots, U_{A}^{n}\right)$ of Chinese evaluated 31 regions. Sorting each components of the vector $U$ from large to small, we get the sort order of different region logistics development trend, as shown in Table 3 .

\section{Analysis of the Evaluation Results}

We could roundly analyze to the evaluation results shown in the Table 3 as the following:

(1) Urban logistics industry competitiveness are closely related with the economic situation of the whole city, logistics facilities and equipment, logistics industry costs, attractiveness of foreign investment, trade and information etc.. Competitive cities are superior to weak competitiveness cities in these indexes in Table 3. In addition, in the process of evaluation, the use of fuzzy consistent judgement matrix to calculate the weights of these indexes is also larger than other. Therefore, the various decision-making which are about the regional logistics industry development should be focused on these indexes. It is necessary to point out that the regional economic conditions are closely related to the level of the regional logistics industry development. The regional logistics industry development has a strongly pulling effect for the regional economic development, and the regional economic development has a reverse effect on the regional logistics system, which can pro- mote its development. Thus the two aspects are interdependent and mutually prerequisite.

(2) It is a step-by-step process that the development of the urban logistics industry and enhancing the overall competitive strength of the city. Because it involves many factors, and in particular the construction of logistics infrastructure needs huge amount of investment, based on their own status of the logistics industry competitive strength which compared with surrounding areas, every region should think carefully, and rationally analyze and make a strategic decision. In working out various policy measures about the regional logistics development planning, firstly, it must be identified that their own strengths and weaknesses of the logistics industry, and it should have a systematic and in-depth analysis to these factors such as production conditions, supply and demand conditions, and support industries and so on, which are related with logistics industry development so that it can be located accurately that the development of the urban logistics industry. At the same time, it should pay attention to the coordination between the regions and attach importance to the complementary and sharing of logistics resources in the same economic, and avoid the mechanical and blind and redundant construction of logistics projects in the same economic region. If that's the case, it might make these logistics projects no joint forces and have no characteristics or competitive advantages, even idle.

(3) Logistics enterprises are the main part of urban logistics industry, therefore the key measures and strategies of promoting the competitiveness of the logistics

Table 3. Sort order of different region logistics competence

\begin{tabular}{|c|c|c|c|c|c|}
\hline Region & $U_{A}^{k}$ & Region & $U_{A}^{k}$ & Region & $U_{A}^{k}$ \\
\hline Shanghai & 3.500 & Zhengzhou & 0.081 & Yinchuan & -0.241 \\
\hline Peking & 3.185 & Chengdu & 0.072 & Lanzhou & -0.283 \\
\hline Guangzhou & 1.355 & Harbin & 0.045 & Nanning & -0.309 \\
\hline Hangzhou & 0.957 & Changsha & 0.014 & Haikou & -0.331 \\
\hline Nanjing & 0.548 & Xi'an & 0.003 & Guiyang & -0.417 \\
\hline Tianjin & 0.498 & Changchun & -0.007 & & \\
\hline Jinan & 0.444 & Taiyuan & -0.116 & & \\
\hline Shenyang & 0.382 & Chongqing & -0.119 & *Urumchi & 0.010 \\
\hline Shijiazhuang & 0.337 & Kunming & -0.154 & *Xining & -0.148 \\
\hline Fuzhou & 0.135 & Hefei & -0.164 & *Lhasa & -0.082 \\
\hline Wuhan & 0.103 & Nanchang & -0.236 & *Hohhot & -0.009 \\
\hline
\end{tabular}

Note: The statistical original data of partial indexes of Xining, Lhasa, Urumchi and Hohhot were incomplete, so the result of sort order about these cities have windages in Table 3 . 
industry is to increase the strength of urban logistics enterprises. The evaluation results indicate that if the competition of city is strong, the number and overall strength of its logistics business are also strong. It is necessary to give priority to cultivate some logistics enterprises which have characteristics, brand effects and strong exemplary role in urban development of the logistics industry. The world famous logistics companies such as UPS, FedEx, DHL, and APL are positioning their own different characteristics, thereby forming its own unique, differentiated competitive advantage. Therefore, local governments should not only innovate in logistics management mechanism, but also strengthen macro guidance to the logistics enterprises, and make efforts to cultivate logistics enterprise groups which have different core business capabilities. All of these are of great significance to promote the regional logistics competitiveness.

(4) The evaluation results show that the Beijing-Tian jin-Hebei Economic Area with Beijing and Tianjin as the representative, the Yangtze River Delta Economic Area with Shanghai and Nanjing as the representative, and the Pearl River Delta Economic Zone with Guangzhou and Shenzhen as the representative are relatively developed and have stronger competitive power in the logistics industry. This is mainly because these three economic zones have stronger economic strength, and the development of the logistics industry has a stronger economic base. In addition, the geographical position and macroeconomic environment of these three economic zones are better, and these provide unique favorable conditions for the development of the logistics industry. We discuss these three economic zones respectively as follows:

1) Beijing-Tianjin-Hebei Economic Area: The Beijing-Tianjin-Hebei Economic Area is located in the heartland of the around Bohai sea economic circle, and it is one of the most intensive areas of the Chinese city zones, industrial parks and port area. In the coastline of Beijing-Tianjin-Hebei Economic Area, Tianjin port is in the middle, and the Huanghua Port, Jingtang Port and Qinhuangdao Port respectively are in the left and right, the throughput of Tianjin and Qinhuangdao Port are more than 100 million tons. Around the four major ports, there are vertical and horizontal cutting railway and highway traffic net. Through these transportation network, Beijing-Tianjin-Hebei Economic Area and its surrounding areas are closely related. The Beijing International Airport and Tianjin international airport have become the Beijing-Tianjin-Hebei Economic Areas' international air cargo centre. Therefore, the Beijing-TianjinHebei Economic Area has developed economy and talents. It is relatively perfect in logistics infrastructure. Also the Beijing-Tianjin-Hebei Economic Area is the heartland of China and northeast Asia's junction, and it connect the north and northwest China, and face the Pa- cific, therefore, it has geographical superiority to develop modern logistics industry in the Beijing-Tianjin-Hebei Economic Area. Also because of the 2008 Beijing Olympic Games, the Beijing-Tianjin-Hebei Economic Area has brought further development and new opportunities and has injected new vitality for the logistics industry. The logistics industry of the Beijing-Tianjin-He bei Economic Area is expected to achieve greater development.

2) The Yangtze River Delta economic zone: The Yangtze River Delta economic zone is located in the entrance of the Yangtze river to the sea. It is one of the largest core economic zones in China. There are $600 \mathrm{~km}$ coastline and many ports like Shanghai, Ningbo, Hong Kong, Nanjing, Zhenjiang which can reach more than 160 countries and regions by sea in the Yangtze River Delta economic zone. The air and land transport are also highly developed, the Shanghai Pudong Airport and Hongqiao Airport have become the international air cargo centre of the Yangtze River Delta economic zone. Advanced highway and the railway network are also excellent in China. In the Yangtze River Delta economic zone, the integrated transport system has been preliminarily formed through the common development of the various modes of transportation such as highways, waterways, rail, air, pipeline and other transportation mode, coupled with favorable natural conditions and obvious geographical advantages, the Yangtze River Delta Economic Zone has become one of the most dynamic economic regions of China's logistics industry development.

3) The Pearl River Delta Economic Zone: The Pearl River Delta Economic Zone is the first known to the Chinese economic region, one of the earliest beneficial areas of the policy of reform and opening-up in China. The obvious geographical advantages and preferential policies have brought unprecedented prosperity. In the economic area, we can find intensive industries, capital-intensive and talent-intensive. Like the Yangtze River Delta economic zone, the superiority of transportation system is prominent in the Pearl River Delta Economic Zone. There are five big ports like Guangzhou Port, Shenzhen Port, Zhanjiang Port, Shantou ports and Zhuhai port. It has five big airports such as Hong Kong, Shenzhen, Guangzhou, Zhuhai and Macao. BeijingGuangzhou, Beijing-Kowloon, and Beijing-Zhuhai Railway all pass through Pearl River Delta Economic Zone. And its internal, high-speed transportation network is also developed. The PRD has formed the three-dimensional, international and all-round development traffic patterns, and the logistics industry has become the powerful backing of the regional economic development in the Pearl River Delta Economic Zone.

(5) The evaluation results show that: Imbalance marks the development of the logistics industry in the provin- 
cial capital cities of China. The development of the logistics industry has a strong gap between the Chinese northwest and southwest cities and the cities in the three major economic regions. In the three major economic regions, the urban logistics industry is more competitive, while in the northwest and south-western cities, the logistics industry is less competitive, especially in the north-western cities, logistics industry is in the weak position. The natural and social environments jointly lead to the imbalance of logistics industry development, and also the unbalanced problems of economic development urgently need to be solved in China.

In China's western regions there are 10 provinces, municipalities, and autonomous regions. It has a total land area of about 5.4 million square kilometres, accounting for $56 \%$ of China's total land area, but the geographical location disadvantage is obvious, with its fragile ecological environment, low industrial intensity, and economic underdevelopment. Also its logistics infrastructure construction is lagging behind. Although there are the Eurasian continental bridge, the Southern Xingjian Railway, the Lanzhou-Kunming railway, the Lanzhou-Xingjian double-track railway in these regions, and in recent years some of the high-level road network construction has provided a solid foundation for the western China logistics industry development, however, compared with the economically developed eastern and south-eastern coastal areas who own three-dimensional, international and all-round development traffic patterns, the gap is still large, and the gap is expanding year by year. At the same time, as the regional logistics industry main part, the logistics enterprises have a lot of problems such as shortage of funds, single mode of services, inflexibility mode of operation, lack of understanding of logistics services, small enterprises scale, the low level of information processing methods, and backward knowledge of modern logistics, shortage of logistics personnel and so on, all of which have made it hard for many of the western region logistics enterprises to achieve greater development in short term. Essentially, it is the main reason that the regional economy is underdeveloped, which leads to the issues of western logistics industry development backwardness. Based on the above analysis, some suggestions on the development of the logistics industry in the west regions can be made as follows:

1) In the long run, we should improve and protect the ecological environment, and create a good environment for the economy and sustainable development of society. In the western regions, especially in the north-west regions, great importance should be attached to the protection of the ecological environment from strategic perspective, and great effort should be made to change the phenomena of high input, low output and, the excessive cost of raw materials and energy so as to achieve the benign circulation of regional economic development and improvement of the ecological environment. This will substantially benefit the development of regional logistics and relevant industries.

2) Continue to enhance the construction of logistics infrastructure in the western region such as railways, highways, airports, river ports, communication and so on in order to provide good hardware environment for the regional economic development.

3) In order to create logistics demand, it is crucial that logistics industrial intensity be improved. In the west regions we should strengthen urban industrial technology, promote industrial upgrading, improve the industrial intensity. PRD model has provided a useful example for the western regions to improve their industrial intensity.

4) The reasonable logistics system planning is necessary. Based on the planning, gradually standardize regional logistics market, integrate and coordinate the regional logistics resources, improve the technical level and efficiency of the logistics operation, seek the process of high value-added logistics, the aim is to reduce regional logistics costs and increase market competitiveness. At the same time, the western regions need to strengthen the cooperation and exchange with the other three major economic regions in the development of the logistics industry, and borrow their successful experiences.

5) Pay attention to the construction of the soft environment during the development of regional economy and regional logistics industry, which includes the conversion of concept, the upgrading of the ability of independent innovation, system innovation and the introduction and training of human resources, so as to enhance the development of the inherent strength and power.

In short, the development of the logistics industry and the improvement of competitiveness in the west regions involve many disadvantageous factors, which makes it hard and a long way to go to attain the current status of the developed regions in east China.

\section{Concluding Remarks}

In this paper a systematic and comprehensive hybrid index evaluation system of regional logistics competitiveness is designed according to the characteristics of China's regional logistics system under supply chain globalization environments, and systematic analysis and discussion of the connotation of the various factors in the index evaluation system are made. Also a comprehensive evaluation of the development trend of logistics industry of China's four municipalities, and 27 provincial capital cities have been done on base of hierarchy analysis thought and fuzzy pattern recognition principles accord- 
ing to 2007 Statistical Yearbook of the National Bureau of Statistics data. The results showed that:

1) Urban logistics industry competitiveness is closely related with the economic situation of the whole city, logistics facilities and equipment, logistics industry costs, attractiveness of foreign investment, trade and information etc.

2) Overall, the regional logistics industry in China has made gratifying development in recent years, but the development level of logistics industry in the provincial capital cities in China remain seriously unbalanced. The Beijing-Tianjin-Hebei Economic Area with Beijing and Tianjin as the representative, the Yangtze River Delta Economic Area with Shanghai and Nanjing as the representative, and the Pearl River Delta Economic Zone with Guangzhou and Shenzhen as the representative are relatively developed and have stronger competitive power in the logistics industry, but in the cities in northwest and southwest regions, the logistics industry is less competitive. And especially in those cities in the northwest regions, logistics industry is in the weakest position.

3) The regional economic development is increasingly dependent on the development level of the regional logistics industry system. To enhance the competitiveness of the regional logistics industry has an important strategic significance for improving the ability to cope with the rising cost and boosting the regional economic development.

\section{Acknowledgement}

The authors would like to thank the referees for their helpful suggestions. This research works was supported by the Natural Science Foundation of Shandong Prov. China under Grant No.Y2008H08 and the Soft Science Foundation of Shandong Prov. China named Logistics Service Innovation Tactics and Pattern of Productive Service Enterprise and the Dr Foundation of Shandong
Prov. China under Grant No. 2008BS014 and the Excellent Teachers of General Institutions of Higher Learning of shandong province international cooperation training Program and the Innovative Team Construction of Ludong University under Grant No.22480301.

\section{REFERENCES}

[1] D. Simchi-Levi, P. Kaminsky, and E. Simchi-Levi, "Designing and managing the supply chain," Irwin/McGrawHill: San Francisco, 2003.

[2] T. L. Saaty, "Multicriteria decision making: The analytic hierarchy process [M]," Pittsburgh, PA: RWS Publications, 1988.

[3] B. Q. Hu, "Fuzzy theoretical basis (in Chinese)," Wuhan: Wuhan University Press, 2004.

[4] J. J. Xie and C. P. Liu, "Fuzzy mathematics method and application," Wuhan: Huazhong University of Science and Technology Press, 2000.

[5] L. A. Zadeh, "Fuzzy sets," Information and Control, No. 8, pp. 338-353, 1965.

[6] R. Bellman and L. A. Zadeh, "Decision making in a fuzzy environment," Management Science, No. 17, pp. 141-161, 1970.

[7] National Bureau of Statistics of China, "China statistical summary in 2007 (in Chinese)," Peking: Statistics of China Press, 2007.

[8] China Economic Prosperity Monitoring Center, "20062007 national economic and social development statistical data compilation," Beijing: China Statistics Press, May 2007.

[9] National Bureau of Statistics of China, "China Statistical Yearbook in 2007 (in Chinese)," Peking: Statistics of China Press, 2007.

[10] L. S. Li and K. K. Lai, "Fuzzy dynamic programming approach to hybrid multiobjective multistage decision-making problems [J]," Fuzzy Sets and Systems, No. $117,2001$. 